\title{
Oordeelsvorming rond de prestatiebeoordeling
}

\section{Samenvatting proefschrift*}

Deze studie bevat het verslag van een onderzoek naar de oordeelsworming in het kader van de beheersing van activiteiten in produktieorganisaties. Enerzijds ging het daarbij om de individuele en veelal subjectieve oordeelsvorming door functionarissen die de prestatiebeoordeling dienen te verrichten (zogenaamde beheerders, 'controllers', dan wel stafmedewerkers die het 'voorwerk' doen voor hun superieuren), anderzijds om de ontwikkeling van plannings- en beheersingssystemen in hun natuurlijke omgeving. Getracht is om beide aspecten zowel theoretisch als empirisch te analyseren. Het eerstgenoemde aspect - het individuele - is toegespitst op de beoordeling (in een laboratorium-experiment) van verschillen tussen plan of budget enerzijds en de uiteindelijke resultaten anderzijds (de zogenaamde verschillenanalyse). Het tweede aspect - het organisatorische - is in grote mate gestuurd door de recente ontwikkelingen van een beheersingssysteem in een 'echte' organisatie. Niet onderzocht zijn de samenhangen tussen deze twee aspecten, hoewel deze - tenminste in de 'praktijk' - niet van belang ontbloot zijn.

Voorts is in het kader van dit onderzoek aandacht geschonken aan methodologische aspecten. Deze betreffen het vakgebied van de financieel-economische gegevensverstrekking (accounting), in het bijzonder de problemen die voortvloeien uit het feit dat dit vakgebied aan verschillende, deels strijdige eisen heeft te voldoen. Het gaat hierbij met name om de eisen die gesteld worden aan de ondersteuning van de besluitvorming enerzijds en de fundering van de verantwoording aan de rechtmatige eigenaars anderzijds. Deze twee gezichtspunten vormen de belangrijkste paradigmata voor de beoefenaren van het vakgebied. Daarom is een overzicht gegeven van het vakgebied en de daarin te onderscheiden specialisaties en benaderingen. Tenslotte wordt een suggestie gedaan voor de verdere ontwikkeling van het

* Zie J. H. R. van de Poel, Judgment and Control: Individual and Organizational Aspects of Performance Evaluation, Wolters-Noordhoff, Groningen, 1986.

Bij de opzet en uitvoering van het onderzoek is samengewerkt met Dr. D. W. Feenstra, die zich in het bijzonder heeft beziggehouden met de oordeelsvorming rond de externe berichtgeving.

Zie D. W. Feenstra, Oordeelsuorming rond de externe berichtgeving, Wolters-Noordhoff, Groningen, 1985. Prof. Dr. J. L. Bouma heeft beide dissertatie-onderzoekingen als promotor begeleid. 
vakgebied. Dit betreft de zogenaamde ontwerpende benadering [zie Ackoff, 1981a en b; alsmede Bouma, 1982].

\section{Referentiepunten en voorkeur}

De laboratorium-experimenten aan de hand waarvan het onderzoek naar de subjectieve oordeelsvorming van 'controllers' werd verricht, is grotendeels gebaseerd op de zogenaamde prospecttheorie [Kahneman en Tversky, 1979; Schoemaker, 1980 en 1982]. In deze - cognitief - psychologische theorie wordt onder meer tot uitdrukking gebracht, dat de menselijke keuze dikwijls, zo niet altijd, berust op een afweging van de verschillen tussen de ter keuze staande alternatieven ten opzichte van een min of meer 'toevallig' vertrekpunt, aangeduid als 'referentiepunt'.

In de literatuur wordt regelmatig verslag gedaan van onderzoek dat de juistheid van dit onderdeel van de prospecttheorie bevestigt. Door het 'manipuleren' van de informatie die aan proefpersonen wordt verstrekt kan aldus vaak worden aangetoond dat de keuze inderdaad berust op een dergelijke procesgang. In het bijzonder gaat het daarbij om de constatering dat mensen onder bepaalde, doorgaans realistische omstandigheden, geneigd zijn hun voorkeur te laten afhangen van de presentatie der gegevens. Ingeval van een keuze uit twee alternatieven, blijken veel mensen geneigd te zijn tot voorkeurswisseling oftewel 'preference shift'. De verklaring voor dit verschijnsel is niet 'rond'. Voorlopig houdt men het erop dat het veroorzaakt wordt door het ervaringsfeit dat de risicohouding van de meeste mensen, sterk beïnvloed wordt door de omstandigheid of de keuze gedaan wordt uit negatieve verschillen ('verliezen') dan wel positieve verschillen ('winsten').

Uit veel onderzoek blijkt dat mensen meer geneigd zijn tot het aanvaarden van risico's als het gaat om 'verliezen' dan wanneer het gaat om 'winsten'. Dit komt ook dikwijls naar voren in allerlei 'dagelijkse' situaties, waarin geconstateerd kan worden dat velen er geen been in zien om veel op het spel te zetten als zij zich reeds in een verliespositie bevinden, terwijl men voorzichtiger is als er al wat verdiend is. Een andere aanleiding tot voorkeurswisseling ligt uitsluitend in de wijze waarop de keuzemogelijkheden geformuleerd worden. Zo laten sommige mensen zich beïnvloeden door het verschil tussen de woorden 'sterfgevallen' respectievelijk 'overlevenden', hoewel het om exact dezelfde keuze gaat.

Ook in de economische literatuur wordt regelmatig verslag gedaan van onderzoek dat de juistheid van dit onderdeel van de prospecttheorie bevestigt [zie o.a. Grether en Plott, 1982; Pommerehne et al., 1982; Slovic en Lichtenstein, 1983]. Gezien het belang van de analyse en beoordeling van budgetverschillen in de praktijk van vrijwel iedere organisatie, ligt een poging om de prospecttheorie toe te passen in het kader van de verschillenanalyse voor de hand. Immers, het gaat daarbij in eerste aanleg om het opsporen van relevante verschillen van de werkelijk verkregen uitkomsten ten opzichte van een budget of plan.

Zowel in de opleidingen als in de praktijk wordt ruimschoots aandacht 
geschonken aan de gebruikelijke technieken op dat gebied. De verschillenanalyse lijkt sterk op de situaties welke door de cognitief-psychologische onderzoekers worden aangemerkt als zijnde geschikt voor voorkeurswisseling. De tekens van de verschillen - positieve of negatieve afwijkingen bepalen immers de basis van de verschillenanalyse en wanneer het referentiepunt, in het geval van de budgettering het plan, gewijzigd zou worden, kan dit gevolgen hebben voor de persoonlijke oordeelsvorming door de desbetreffende functionarissen. De prospecttheorie vraagt als het ware om een toepassing op de budgettering.

In hoofdstuk 4 wordt verslag gedaan van een serie experimenten waarin de proefpersonen worden 'gemanipuleerd' door een wijziging van het plan (budget), zonder dat zulks de verhoudingen tussen de prestaties van de te beoordelen objecten (in dit geval fictieve organisatie-eenheden) aantast. Aan de experimenten werd deelgenomen door praktijkmensen en door studenten die door hun opleiding (aan de Faculteit der Economische Wetenschappen te Groningen, resp. de Nivra-opleiding tot registeraccountant) goed op de hoogte zijn van de 'ins' en 'outs' van de analyse van budgetverschillen. Nagegaan werd of en in hoeverre de proefpersonen gevoelig waren voor de manipulatie.

Uit het onderzoek bleek dat de voorkeur van de meeste proefpersonen inderdaad onderhevig is aan verandering van het plan. Echter, niet op de wijze en in de mate die op grond van de prospecttheorie verwacht zouden mogen worden. De reden hiervoor ligt in de bereidheid en het vermogen van de proefpersonen om betekenis toe te kennen aan de verstrekte gegevens op grond van hun (voor)oordelen omtrent het doel van de budgettering en de verschillenanalyse. In concreto: ruwweg de helft van de proefpersonen is van oordeel dat een begrotingstekort en een begrotingsoverschot asymmetrisch moeten worden beoordeeld. Indien een afdeling een tekort heeft, telt dit zwaar mee in de uiteindelijke beoordeling, maar indien er een overschot is, wordt (vrijwel) uitsluitend gelet op de omvang van de output van de te beoordelen afdelingen. De overige proefpersonen letten in hoofdzaak op de verhouding tussen (financiële) input en output en aangezien deze grootheden in de verschillende experimentele opdrachten steeds een zelfde waarde kregen, wordt door deze groep in feite niet gereageerd op de experimentatie.

\section{Individuele verschillen}

In hoofdstuk 5 is vervolgens gepoogd de verschillen welke tussen de individuele proefpersonen geconstateerd konden worden, te relateren aan enkele veel gebruikte methoden voor het meten van persoonlijke kenmerken van beslissers. Hierbij zijn onder andere gebruikt een indeling van Hopwood [1972 en 1973] van een drietal evaluatie-stijlen, een test van MacDonald [1970] voor de meting van de effecten van dubbelzinnige gegevensverstrekking en een test die gebaseerd is op een indeling van persoonlijkheden van Jung (de zogenaamde 'Jungian typology') [Jung, 1921; Mitroff en Kilman, 1976; Keen en Bronsema, 1981]. De verklaring die met behulp van deze 
methoden kon worden verkregen, is evenwel ontoereikend.

De indeling van Hopwood maakt gebruik van de volgende stijlen voor de beoordeling van prestaties:

1 de budget-constrained (oftewel formula-based) stijl: er wordt vooral gelet op de specificaties van het budget (in dit geval de toegewezen financiële middelen), terwijl andere, veelal inhoudelijke aspecten worden verwaarloosd;

2 de non-accounting (oftewel subjectieve) stijl: financieel-economische informatie speelt slechts een ondergeschikte rol, men let vooral op inhoudelijke aspecten, bijvoorbeeld kwaliteit en omvang van de output;

3 de profit-conscious stijl (een combinatie van 1 en 2): de beoordeling wordt zo veel mogelijk gebaseerd op het langere termijn vermogen van de organisatie om effectief te blijven opereren; financieel-economische informatie wordt wel gebruikt, maar is slechts een (veelal gebrekkige) indicatie van de effectiviteit op langere termijn.

De Hopwood classificatie bleek inderdaad verband te houden met de resultaten van de experimentele opdrachten. Proefpersonen met een budgetconstrained evaluatiestijl zijn degenen die in het algemeen bereid zijn zich te laten leiden door de verstrekte informatie omtrent de normen en standaards. Naarmate men zich minder laat gelegen aan de vooraf gestelde normen, blijft het oordeel constant. Dit resultaat werd uiteraard verwacht en het is als zodanig niet opzienbarend, maar het vormt een verbinding tussen de prospect-theory en de literatuur op het gebied van de management accounting, in het bijzonder met betrekking tot de gedragswetenschappelijke tak daarvan ('behavioral accounting research' en 'human information processing', zoals onder andere weergegeven door Hogarth [1980] en Libby [1981]).

Van de vele persoonlijkheidsbenaderingen [zie o.a. Seiler en Bartlett, 1982] die in de accounting literatuur worden genoemd voor de verklaring van individuele verschillen in de beoordeling van prestaties, werd in deze studie gekozen voor resp. die van MacDonald [1970], een eigen methode voor de bepaling van het vertrouwen dat de evaluator in zijn beslissingen stelt ('decision confidence' oftewel zelfvertrouwen), en de op Jung [1921] gebaseerde indeling ('environmental interaction theory').

De bijdrage aan de verklaring van de individuele verschillen in beoordeling in dit experiment waren evenwel gering. MacDonalds 'tolerance for ambiguity' toets leverde niets op, behalve een zwak verband met de score voor 'zelfvertrouwen' (correlatiecoëfficiënt van 0,47 , significantie 0,90 ).

\section{De organisatorische context}

Het tweede aspect - de organisatorische context van de prestatiebeoordeling - is behandeld in hoofdstuk 6 . Aan de hand van een viertal theorieën over organisaties - niet alle even ver ontwikkeld - is getracht de recente veranderingen aan het bedrijfsvoeringssysteem van de Rijksuniversiteit te Gro- 
ningen te reconstrueren. De gehanteerde theorieën zijn:

1 de transactiekostentheorie van Williamson [1973 en 1975], waarin een comparatieve analyse van de transactiekosten (afstemmingskosten) van verschillende coördinatiemechanismen centraal staat;

2 de agency-theory - speciaal de versie van Jensen [1983] - die het accent legt op de bewuste en onbewuste processen waarin mensen in organisaties overeenkomsten sluiten;

3 de contingentietheorie (speciaal de uitwerking van J. R. Galbraith [1973 en 1974] welke bekend staat als de 'information-processing approach');

4 de distortie-benadering, een verzameling gezichtspunten waarin speciaal gelet wordt op de verdraaiing en bewuste vertekening van informatie door participanten [zie o.a. Kaplan, 1983 en 1984; Birnberg et al., 1983; Lawler, 1976].

De recente aanpassingen van het bedrijfsvoeringssysteem van de Rijksuniversiteit te Groningen betreffen in hoofdzaak de volgende elementen:

1 de invoering van een systeem van meerjarenbegroting, met kleine jaarlijkse bijstellingen en gekoppeld aan een lange termijn beleidsplanning;

2 de invoering van een systeem van door-en toeberekenen van overheadkosten en service-kosten;

3 de introductie van een lump-sum toewijzing van middelen in plaats van een systeem van oormerking;

4 het openen van de mogelijkheid om (intern) te sparen en te lenen, in plaats van het beslagleggen op overschotten;

5 het invoeren van output-metingen en prestatiebeoordeling terzake van de hoofdtaken onderwijs en onderzoek.

Veel van deze aanpassingen laten zich verklaren door een of meer van de geselecteerde theorieën. Aldus vindt een toetsing plaats van de gehanteerde theorieën en tevens is het mogelijk aan de hand van de theorie enige gebreken en leemten in het systeem op te sporen, bijvoorbeeld:

- het ontbreken van een expliciete analyse van het vraagstuk van de verdeling van risico's over de verschillende afdelingen en functionarissen;

- het ontbreken van een duidelijke beloningsstructuur;

- het hinken op twee (strijdige) gedachten waar het gaat om het instellen van kostencentra dan wel winstcentra voor de daarvoor in aanmerking komende afdelingen;

- het ontbreken van een waarlijke autonomie voor de instelling in relatie tot de financier.

\section{Methodologische aspecten}

Tenslotte wordt in het kader van dit onderzoek aandacht geschonken aan methodologische aspecten. Enkele hiervan komen aan de orde in de hoofdstukken 2 en 3 , en betreffen respectievelijk het vakgebied van de financieeleconomische gegevensverstrekking ('accounting') en de problemen die voortvloeien uit het feit dat het vakgebied aan verschillende, deels strijdige 
eisen heeft te voldoen. De 'double bind' relatie tussen theorie en praktijk zoals Schreuder [1983] het noemt. In het laatste geval gaat het dan met name om de eisen die gesteld worden aan de ondersteuning van de besluitvorming enerzijds en de fundering van de verantwoording aan 'rechtmatige' eigenaars anderzijds. Deze twee gezichtspunten vormen de belangrijkste paradigmata voor de beoefenaren van het vakgebied. Daarom is in hoofdstuk 2 tevens een overzicht gegeven over het vakgebied en de daarin te onderscheiden specialisaties en benaderingen. In hoofdstuk 6 wordt een suggestie gedaan voor de verdere ontwikkeling van het vakgebied. Dit betreft de zogenaamde ontwerpende benadering van Ackoff [1981a en b].

De ontwerpende benadering tracht een synthese te zijn van de persoonlijke oordeelsvorming (Bouma spreekt van de 'beschouwende' benadering) waarin subjectieve en door de ervaring in de praktijk gevormde redeneerschema's worden toegepast, en de analytische benadering welke de nadruk legt op het uiteenrafelen van problemen en het expliciet modelleren. In de ontwerpende benadering wordt voorts een grote waarde toegekend aan het creatief vermogen en de verbeeldingskracht van de beslissers. Aldus wordt tot uitdrukking gebracht dat

- organisaties vaak sneller moeten worden 'geholpen' dan de analytische benadering oplossingen kan aandragen;

- niet alleen afgegaan kan worden op gegevens die betrekking hebben op het verleden;

- de oplossing(en) niet moeten leiden tot nieuwe, en wat erger is, grotere problemen ('neveneffecten');

- gebruik gemaakt moet worden van aanwezige leercapaciteiten in de organisatie, alsmede van de bereidheid om ('echt') te experimenteren.

De in hoofdstuk 6 besproken organisatietheorieën worden opgevat als 'basiselementen' voor de toepassing van de ontwerpende benadering. Deze ontwerpende benadering vertoont qua methodologische status verwantschap met de kunstleer. Dat wil volgens Klant [1985] zeggen, dat niet wordt voldaan aan de eis van falsifieerbaarheid, maar dat het accent ligt op de idealisatie van het empirisch object en op de plausibiliteit van de veronderstellingen. Het is derhalve niet uitgesloten, dat de besproken theorieën zich alleen dan voor toetsing lenen, wanneer zij in de praktijk zijn gebracht nadat zij eerst slechts leefden als 'idee' (zie ook Feenstra en Van de Poel, 1985 en Van de Poel en Tempelaar, 1986). Het probleem dat zich hierbij voordoet, is hoofdzakelijk filosofisch van aard en het is in het kader van deze studie dan ook niet verder onderzocht. De meer aprioristische benaderingen (her)winnen echter ontegenzeggelijk veld in de bedrijfseconomie. In het vakgebied 'berichtgeving' bijvoorbeeld, heeft de agency theory thans een zeer dominante plaats ingenomen (zie bijvoorbeeld Watts en Zimmerman, 1986), een plaats die alle kenmerken vertoont van wat in Lakatos' [1970] termen 'hard core' genoemd wordt. De bemoeienis van de methodologie en de filosofie met de bedrijfseconomie zal daarom nog wel niet op korte termijn gestaakt kunnen worden. 


\section{Literatuur}

Ackoff, R. L. [1981a] Creating the Corporate Future, John Wiley and Sons, New York.

Ackoff, R. L. [1981b] The Art and Science of Mess Management, Interfaces, Vol. 11, No. 1.

Birnberg, J. G., Turopolec, L., Young, S.M. [1983] The Organizational Context of Accounting, Accounting, Organizations and Society, Vol. 8, No. 2/3.

Bouma, J. L. [1982] Leerboek der bedrijfseconomie, deel I, Delwel, Wassenaar.

Feenstra, D. W. [1985] Oordeelsvorming rond de externe berichtgeving, Wolters-Noordhoff, Groningen.

Feenstra, D. W., van de Poel, J. H. R. [1985] Bedrijfseconomie, Methodologie en Besluitvorming I, II en III, Maandblad voor Accountancy en Bedrijfshuishoudkunde, januari, februari en maart.

Galbraith, J. R. [1973] Designing Complex Organizations, Addison-Wesley Publishing Company, Reading.

Galbraith, J. R. [1974] Organizational Design: An Information Processing View, Interfaces, Vol. 4, No. 3 (pp. 28-36).

Grether, D. M., Plott, C. R. [1983] Economic Theory of Choice and the Preference Reversal Phenomenon, American Economic Review, Vol. 69, No. 4 (pp. 623-638).

Hogarth, R. M. [1980] Judgment and Choice, John Wiley \& Sons, New York.

Hopwood, A. G. [ 1982] An Empirical Study of the Role of Accounting Data in Performance Evaluation, Supplement to the Journal of Accounting Research.

Hopwood, A. G. [1973] An Accounting System and Human Behaviour, Saxon House, London. Jensen, M.C. [1983] Organizations Theory and Methodology, The Accounting Review, Vol 58, pp. 319-339.

Jung, C. G. [1921] Psychological Types, Routledge \& Kegan Paul Ltd., London.

Kahneman, D., Tversky, A. [1979] Prospect Theory: an analysis of decision under risk, Econometrica, Vol. 47, No. 2.

Kaplan, R. S. [1983] Measuring Accounting Research, The Accounting Review, Vol. 58, No. 4.

Kaplan, R. S. [1984] The Evolution of Management Accounting, The Accounting Review, Vol. LIX, No. 3.

Keen, P. G. K., Bronsema, G. L. [1981] Cognitive Style Research: A Perspective for Integration, Unpublished Paper, Sloan School of Management.

Lakatos, I. [1970] Falsification and the Methodology of Scientific Research Programmes, in Lakatos, I., Musgrave, A., eds., Criticism and the Growth of Knowledge, Cambridge University Press, Cambridge.

Lawler, E. E. [1976] Control Systems in Organizations, in Dunnette, M.D., ed., Handbook of Industrial and Organizational Psychology, Rand McNally College Publishing Comp., Chicago.

Libby, R. [1981] Accounting and Human Information Processing, Prentice-Hall, Inc., Englewood Cliffs.

MacDonald, A. P. [1970] Revised Scale for Ambiguity 'Tolerance: Reliability and Validity, Psychological Reports, 26 (pp. 791-798).

Mitroff, I. I., Kilman, R. H. [1979] On organizational stories: an approach to the design of organizations through myths and stories, in Kilman, R. H., Pondy, L. R., The Management of Organizational Design, North Holland, Amsterdam.

Poel, J. H. R. van de [1986] Judgment and Control: Individual and Organizational Aspects of Performance Evaluation, Wolters-Noordhoff, Groningen.

Poel, J. H. R. van de, Tempelaar, F. M. [1986] On the Applicability of Positive Agency Theory, Paper presented at the Agency Theory Workshop, Rijksuniversiteit Groningen.

Poel, J. H. R. van de [1985] Desillusies van de economische wetenschap in: J. Muysken en H. Schreuder, Economische wetenschappen: eenheid in verscheidenheid?, Van Gorcum, Maastricht.

Pommerehne, W. W., Schneider, F., Zweifel, P. [1982] Economic Theory of Choice and the Preference reversal Phenomenon: A Reexamination, American Economic Review, Vol. 72, No. 3 (pp. 569-574).

Schoemaker, P. J. H. [1980] Experiments on decisions under risk: The expected utility hypothesis, Nijhoff Publishing Co., Boston.

Schoemaker, P. J. H. [1982] The Expected Utility Model: Its Variants, purposes, Evidence and Limitations, Journal of Economic Literature, Vol. XX (pp. 529-563).

Schreuder, H. [1983] Economic Theories of Organization: An Overview and Asessment of some Recent Developments, $V U$ research memorandum No. 1983-11, Amsterdam.

Seiler, R. E., Bartlett, R. G. [1982] Personality Variables as Predictors of Budget System Characteristics, Accounting, Organization and Society, Vol. 7, No. 4 (pp. 381-403). 
Slovic, P., Lichtenstein, S. [1983] Preference reversals: A Broader Perspective, American Economic Review, Vol. 73, No. 4 (pp. 596-605).

Watts, R. L., Zimmerman, J. L. [1986] Positive Accounting Theory, Prentice Hall, Inc., Englewood Cliffs.

Williamson, O. E. [1973] Markets and Hierarchies: Some Elementary Considerations, American Economic Revieu, May.

Williamson, O. E. [1975] Markets and Hierarchies: Analysis and Antitrust Implications, Free Press, New York. 